\title{
Synaptic Localization and Function of Sidekick Recognition Molecules Require MAGI Scaffolding Proteins
}

\author{
Masahito Yamagata and Joshua R. Sanes \\ Center for Brain Science and Department of Molecular and Cellular Biology, Harvard University, Cambridge, Massachusetts 02138
}

\begin{abstract}
Four transmembrane adhesion molecules-Sidekick-1, Sidekick-2, Down's syndrome cell adhesion molecule (Dscam), and Dscamlike - are determinants of lamina-specific synapse formation in the vertebrate retina. Their C termini are predicted to bind postsynaptic density (PSD)-95/Discs Large/Z0-1 (PDZ) domains, which are present in many synaptic scaffolding proteins. We identify members of the membrane-associated guanylate kinase with inverted orientation (MAGI) and PSD-95 subfamilies of multi-PDZ domain proteins as binding partners for Sidekicks and Dscams. Specific MAGI and PSD-95 family members are present in distinct subsets of retinal synapses, as are Sidekicks and Dscams. Using Sidekick-2 as an exemplar, we show that its PDZ-binding C terminus is required for both its synaptic localization in photoreceptors and its ability to promote lamina-specific arborization of presynaptic and postsynaptic processes in the inner plexiform layer. In photoreceptor synapses that contain both MAGI-1 and PSD-95, Sidekick-2 preferentially associates with MAGI-1. Depletion of MAGI-1 from photoreceptors by RNA interference blocks synaptic localization of Sidekick-2 in photoreceptors without affecting localization of PSD-95. Likewise, depletion of MAGI-2 from retinal ganglion cells and interneurons interferes with Sidekick-2-dependent laminar targeting of processes. These results demonstrate that localization and function of Sidekick-2 require its incorporation into a MAGI-containing synaptic scaffold.
\end{abstract}

\section{Introduction}

At chemical synapses, the nerve terminal is specialized for neurotransmitter release, the postsynaptic apparatus is specialized for signal transduction, structures that mediate release and response are precisely apposed to each other, and appropriate partners are selectively matched to form functional circuits (Craig et al., 2006; McAllister, 2007; Sanes and Yamagata, 2009). Key to all of these processes is the selective association of synaptic components with presynaptic and postsynaptic membranes. Accordingly, proteins that generate and maintain such associations are critical for synaptic development and function. Several intracellular binding partners have been found that are required for localization of particular neurotransmitter receptors in the postsynaptic membrane. These include rapsyn, gephyrin, and members of the postsynaptic density (PSD)-95 family, which are involved in aggregation of acetylcholine, glycine, and AMPA-type glutamate receptors, respectively (Gautam et al., 1995; Feng et al., 1998; Banks et al., 2003; Ehrlich and Malinow, 2004; Prybylowski et al., 2005; Elias et al., 2006; Fritschy et al., 2008). For other synaptic membrane proteins, however, localization and clustering mechanisms remain poorly understood.

Received Dec. 21, 2009; accepted Jan. 13, 2010.

This work was supported by a grant from the National Institutes of Health to J.R.S. We thank Guoping Feng (Duke University) for cDNA libraries, and J. Cartaud (Université de Paris) for antibodies to MAGI-1. M.Y. and J.R.S. designed experiments and wrote the paper. M.Y. performed the experiments.

Correspondence should be addressed to Joshua R. Sanes, Department of Molecular and Cellular Biology and Center for Brain Science, Harvard University, 52 0xford Street, Cambridge, MA 02138. E-mail: sanesj@mcb. harvard.edu.

DOI:10.1523/JNEUROSCI.6319-09.2010

Copyright $\odot 2010$ the authors $\quad 0270-6474 / 10 / 303579-10 \$ 15.00 / 0$
Here, we address this issue with regard to a set of four closely related homophilic adhesion molecules that are localized to specific synapses in retina: Sidekick-1, Sidekick-2, Down's syndrome cell adhesion molecule (Dscam), and Dscam-like-1 (DscamL). Sidekicks and Dscams are expressed by mutually exclusive neuronal subsets in the chick retina, and they mediate selective connectivity among neurons that express the same molecules (Yamagata et al., 2002; Yamagata and Sanes, 2008). Dscams also mediate intercellular interactions in mouse retina, brainstem, and spinal cord (Fuerst et al., 2008, 2009; Ly et al., 2008; Amano et al., 2009).

Sidekicks and Dscams terminate in sequences predicted to bind to PSD-95/Discs Large/ZO-1 (PDZ) domains, 90 aa modules present in numerous scaffolding proteins that are localized at a variety of intercellular junctions, including synapses. PDZ domains bind C-terminal consensus sequences of numerous proteins involved in synaptic differentiation and function. PDZ domain proteins play diverse roles in the trafficking, anchoring, and clustering of neurotransmitter receptors and in linking them to signaling partners and cytoskeletal elements (Hung and Sheng, 2002; Ehrlich and Malinow, 2004; Kim and Sheng, 2004; Funke et al., 2005; Prybylowski et al., 2005; Elias et al., 2006; Feng and Zhang, 2009). We therefore tested the possibility that PDZ domain proteins are also required for synaptic development.

We show here that Sidekicks and Dscams interact with PDZ domain-containing synaptic scaffolding proteins of the membrane-associated guanylate kinase with inverted orientation (MAGI) subfamily (Cho et al., 1992; Hirao et al., 1998; Funke et al., 2005; Feng and Zhang, 2009). In the retina, the three MAGI subfamily members, like Sidekicks and Dscams, are expressed by subsets of retinal neurons, leading to complex combinatorial pat- 
Table 1. Phylogenetic conservation of PDZ domain-binding C termini of Sidekicks and Dscams

\begin{tabular}{lc}
\hline Protein & C terminus \\
\hline Sidekick & \\
Human Sdk1 & QSAGGVYTPAGPGARTPLTGFSSFV \\
Mouse Sdk1 1 & QSAGGVYTPAGPGARAPLTGFSSFV \\
Platypus Sdk1 & GGVYTPSGQQAPGSRTPVTGFSSFV \\
Chicken Sdk1 & GGVYTPTGQPAPGSRTPVTGFSSFV \\
Zebrafish Sdk1 & GGVYTPAGQPAPGSRTPVTGFSSFV \\
Human Sdk2 & STLYRPPSSLAPGSRAPIAGFSSFV \\
Mouse Sdk2 & STLYRPPSSLAPGSRAPIAGFSSFV \\
Platypus Sdk2 & TTLYRPPSSLGPGSRAPIAGFSSFV \\
Chicken Sdk2 & GTLYRPPSSLAPGSRAPIAGFSSFV \\
Xenopus tropicalis Sdk2 & NPIYRPPSSLAPAARAPIAGFSSFV \\
Zebrafish Sdk2 & GTLYRPPSSLAPGSRAPIAGFSSFV \\
Amphioxus Sdk & ALANGMAAGSAPLPGFSSFV \\
Sea urchin Sdk & VYLQNNLAKMQPGSRAPVHGFSSFV \\
Drosophila melanogaster Sdk & LNGGQIIVNNMARSRAPLPGFSSFV \\
Beetle Sdk & LNGGQIIINNMARSRAPLPGFSSFV \\
C. elegans Sdk/rig-4 & DSTSEGPWANIPATPNLTTGFSSFV \\
Dscam & \\
Human Dscam & SQESLLDSRGHLKGNNPYAKSYTLV \\
Mouse Dscam & SQESLLDSRGHLKGNNPYAKSYTLV \\
Chicken Dscam & SQESLLDSRGHLKGNNPYAKSYTLV \\
Xenopus laevis Dscam & SQESLLDSRGHLKGSNPYTKSYTLV \\
Human DscamL & EMSTSGVGRSQKQGAGAYSKSYTLV \\
Mouse DscamL & EMSTPGVGRSQKQGAGAYSKSYTLV \\
Zebrafish Dscam chromosome 5 & QESLLDSRGHLKQSNNPYAKSYTLV \\
Zebrafish Dscam chromosome 10 & QESLLDSRGHLKQTNNPYAKSYTLV \\
Drosophila Dscam CG17800 & ETGPKQLQLQQANGAGFTAYDTMAV \\
Drosophila Dscam2 CG42256 & HEGKIKHNSRLIQHFPNHNISITYL \\
Drosophila Dscam3 CG31190 & EELTSLLARYHEKKEQERLEYTIHVV \\
Drosophila Dscam4 CG42330 & KTKTQTSPRMRANQKLHREAFQINV \\
\hline Sdk, Sidekick. &
\end{tabular}

terns of adhesion and scaffolding proteins. Using Sidekick-2 as an exemplar, we show that interaction with MAGI proteins is necessary for localization and developmental function of this synaptic adhesion molecule in vivo. Together, our results suggest that interaction with synaptic scaffolding molecules is required for target recognition molecules to trigger and regulate synaptic differentiation.

\section{Materials and Methods}

Reagents. Expression vectors and piggyBac transposons encoding mouse Sidekick-1, Sidekick-2, Dscam, and DscamL were described previously (Yamagata and Sanes, 2008). The piggyBac transposon vectors contained a cytomegalovirus (CMV) promoter and enhancer, the Sidekick or Dscam cDNA, and a simian virus 40 polyadenylation signal. In some cases, the cDNA was followed by an internal ribosome entry side and green fluorescent protein (GFP). A Sidekick-2 mutant lacking the C-terminal tripeptide SFV (Sidekick-2 $\Delta$ SFV) was generated by using PCR to replace this sequence with a termination codon (TAG). Fragments of MAGI-1 and SAP102 were cloned into pCMV-Tag3B vector (Stratagene) to obtain myc-tagged constructs. A full-length mouse MAGI-1b tagged with FLAG was obtained from Addgene (Vazquez et al., 2001). cDNA encoding mouse PSD-95 was amplified from P0 mouse brain and fused to Cerulean (cyan) fluorescent protein in pCMV-N1Cerulean. Full-length cDNAs encoding chick MAGI-1, MAGI-2, and MAGI-3 were amplified from E17 chick retina, and cloned into pCMV3Tag-9 (Stratagene) or pCMV-N1-mCherry to fuse to monomeric Cherry red fluorescent protein. Partial cDNA sequences of chick Cipp, Pist/Cal, Chapsyn110, and SAP102 were amplified, cloned into pGEMTeasy vectors (Promega), and used as templates to generate riboprobes for in situ hybridization.
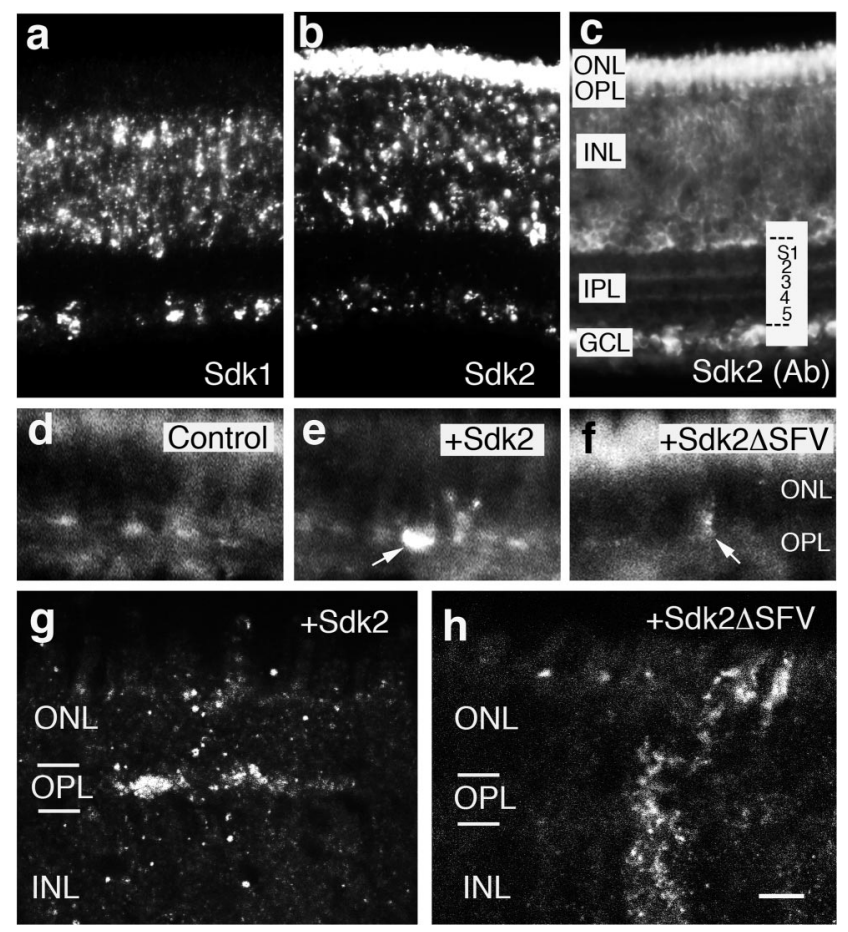

Figure 1. Localization of Sidekick-2 at photoreceptor synapses requires its C terminus. $\boldsymbol{a}, \boldsymbol{b}$, In situ hybridization shows that Sidekick-1 (Sdk1) and Sidekick-2 (Sdk2) are expressed by subsets of retinal cells; only Sidekick-2 is expressed by photoreceptors in E16 chick retina. $\boldsymbol{c}, \boldsymbol{d}$, Retinal section stained with anti-Sidekick-2, showing localization of the protein to the outer plexiform layer (OPL) and sublaminae within the IPL. $\boldsymbol{d}$, Higher-power view of the OPL shows Sidekick-2 at photoreceptor synapse. $\boldsymbol{e}-\boldsymbol{h}$, OPL of E17 retina following piggyBac-mediated introduction of GFP plus Sidekick-2 $(\boldsymbol{e}, \boldsymbol{g})$ or a mutant Sidekick-2 lacking the C-terminal -SFV (Sdk2 SSFV) $(\boldsymbol{f}, \boldsymbol{h})$. The transfected cells were detected by coexpression of GFP (indicated by arrows) and enhanced level of Sidekick. Wild-type and endogenous Sidekick colocalized, whereas mutant Sidekick was diffusely distributed in the inner segment $(\boldsymbol{f})$ or inner segment and bipolar cell (h). ONL, Outer nuclear layer, containing photoreceptors; OPL, outer plexiform layer, containing synapses of photoreceptors on interneurons; INL, inner nuclear layer, containing interneurons; $\mathrm{GCL}$, ganglion cell layer, containing retinal ganglion cells and some amacrine cells. Scale bars: $\boldsymbol{a}-\boldsymbol{c}, 30 \mu \mathrm{m} ; \boldsymbol{d}-\boldsymbol{f}, 10 \mu \mathrm{m} ; \boldsymbol{g}, \boldsymbol{h}, 5 \mu \mathrm{m}$.
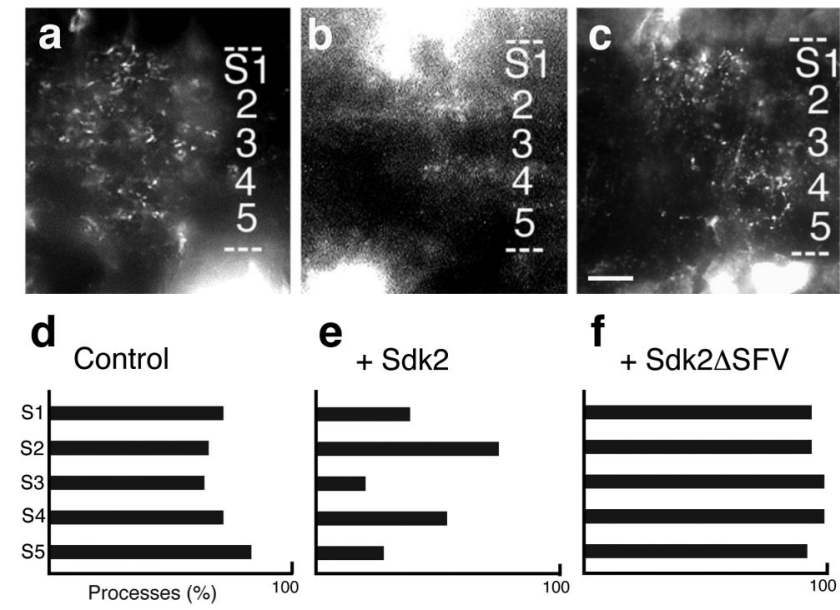

f $+\mathrm{Sdk} 2 \Delta \mathrm{SFV}$

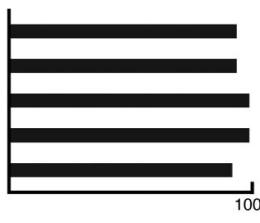

Figure 2. Function of Sidekick-2 in the inner plexiform layer requires its $C$ terminus. $\boldsymbol{a}-\boldsymbol{c}, \mathrm{IPL}$ of E17 retina following piggyBac-mediated introduction of GFP alone $(\boldsymbol{a})$, or with Sidekick-2 (b) or Sidekick-2 $\Delta$ SFV (c). GFP-expressing processes were present in all IPL sublaminae. Ectopic expression of Sidekick-2 biases neurites to S2 and S4 (Yamagata and Sanes, 2008). Deletion of SFV abolishes this effect. Abbreviations as in Figure 1. Scale bars: (in c) $\boldsymbol{a}-\boldsymbol{c}, 10 \mu \mathrm{m}$. $\boldsymbol{d}$-f, Quantification of results from experiments such as those shown in $\boldsymbol{a}-\boldsymbol{c}$. The presence of GFP-positive processes in $51-\$ 5$ was cored in $57-114$ fields from three to seven retinas per construct. Concentration of processes in $S 2$ and $S 4$ was significant for $\boldsymbol{e}$, but not for $\boldsymbol{d}$ or $\boldsymbol{f}\left(p<0.01\right.$ by $\chi^{2}$ test). 
Table 2. Binding of neural cell adhesion molecules to PDZ domains assessed in yeast

\begin{tabular}{|c|c|c|c|c|c|c|c|c|}
\hline & \multicolumn{8}{|c|}{ PDZ proteins [PDZ domain number] } \\
\hline & \multirow{2}{*}{$\begin{array}{l}\text { PSD-95 } \\
{[1,2,3]}\end{array}$} & \multicolumn{2}{|c|}{ Chapsyn110 } & \multirow{2}{*}{$\begin{array}{l}\text { SAP102 } \\
{[1,2,3]}\end{array}$} & \multirow{2}{*}{$\begin{array}{l}\text { MAGI-1 } \\
{[2,3,4]}\end{array}$} & \multicolumn{2}{|l|}{ MAGI-2 } & \multirow{2}{*}{$\begin{array}{l}\text { Pist/Cal } \\
{[1]}\end{array}$} \\
\hline & & {$[2,3]$} & {$[3]$} & & & {$[1,2,3,4]$} & {$[1,2,3]$} & \\
\hline Sidekick-1 (-TGFSSFV) & ++ & ++ & ++ & ++ & ++ & ++ & ++ & ++ \\
\hline Sidekick-2 (-AGFSSFV) & ++ & ++ & ++ & ++ & ++ & ++ & ++ & ++ \\
\hline Dscam (-PYAKSYTLV) & + & ++ & ++ & ++ & ++ & ++ & ++ & + \\
\hline DscamL (-AYSKSYTLV) & + & ++ & ++ & ++ & ++ & ++ & ++ & + \\
\hline NMDAR2B (-KLSSIESDV) & ++ & ++ & + & ++ & - & - & - & + \\
\hline NrCAM (-PVNAMNSFV) & ++ & ++ & ++ & ++ & + & + & ++ & ++ \\
\hline Neuroligin-1 (-PHSHSTTRV) & ++ & ++ & ++ & ++ & - & ++ & ++ & ++ \\
\hline Control & - & - & - & - & - & - & - & - \\
\hline
\end{tabular}

The yeast two-hybrid method was to assess the interaction of the PDZ domain protein fragment with the C-terminal peptides of synaptic membrane protein. ++ , Strong interaction; + , weak interaction; - , no detectable interaction.

For performing RNA interference, the following DNA sequences were cloned into pcDNA6.2-GW/EmGFP-miR (Invitrogen): MAGI-1A, TGCTGACAGCATGGCGATAAAGGTTAGTTTTGGCCACTGACTGACTAACCTTTCGCCATGCTGT; and MAGI-2C, TGCTGTAGACAATCACATCACCTGTTGTTTTGGCCACTGACTGACAACAGGTGGTGATTGTCTA.

They were chained to generate two tandem copies, and transferred to a unique ClaI site of the retroviral plasmid, RCAS-BP(B), together with GFP, as described previously (Yamagata and Sanes, 2008). RCAS replication-competent retroviruses were generated by in vivo electroporation to optic vesicles (see below). As an alternative, the EmGFP-miR cassettes were transferred to pXL-BacII-CAG-Dest plasmid using LR clonase (Invitrogen). This Gateway destination vector pXL-BacII-CAGDest bears an RfA fragment (Gateway vector conversion system, Invitrogen) between CAG promoter (Addgene) and $\beta$-globin polyadenylation signal flanked by piggyBac transposon sequences ( $\mathrm{Li}$ et al., 2001).

Antibodies to Sidekick-1, Sidekick-2, Dscam, and DscamL were described previously (Yamagata et al., 2002; Yamagata and Sanes, 2008). The antibodies were generated to chick antigens, but antibody CS22, to Sidekick-2, cross-reacts with mouse Sidekick-2. A rabbit polyclonal antibody to mouse MAGI-1 was a gift from J. Cartaud (Université de Paris, Paris, France) (Strochlic et al., 2001). This antibody was generated to the peptide CPRNPPEQRRRPYKE; the final 9-mer is perfectly conserved in chick. Anti-PSD-95 (IgG2a) was from Affinity BioReagents; monoclonal antibodies to visinin, synaptotagmin (monoclonal antibody 48), synaptic vesicle 2 (SV2), and myc (9E10) were from Developmental Studies Hybridoma Bank; monoclonal antibodies to pan-PDZ (pan-MAGUK) and chapsyn110 were from NeuroMab; rabbit anti-MAGI-2 (M2441) and anti-FLAG were from Sigma; mouse anti-MAGI-3 (612676) was from BD Biosciences; rabbit anti-myc was from Immunology Consultants Laboratory; and secondary antibodies were from Invitrogen.

Yeast two-hybrid screening. Yeast two-hybrid screening (Fields and Song, 1989) was performed using BD Matchmaker Two-Hybrid System 3 (Clontech) essentially as described in the manufacturer's protocol. Bait cDNA segments corresponding to C-terminal segments of mouse Sidekick-1 or Sidekick-2 were cloned into the EcoRI/SalI site of pGBKT7. Mouse brain and spinal cord cDNA libraries in HybriZAP (Stratagne) were gifts from G. Feng (Duke University, Durham, NC). The growth of yeast strain AH109 was monitored on-Ade/-His/-Leu/-Trp plates.

In ovo electroporation. RCAS plasmids or a 10:1 mixture of transposon plasmid(s) and a piggyBac transposase plasmid were injected into the optic vesicles of E2 (Hamburger-Hamilton stage 9-11) chick embryos. Electroporation was with three square pulses of $7 \mathrm{~V}$ for $25 \mathrm{~ms}$ using ECM830 (Harvard Apparatus). Embryos were fixed with 4\% (w/v) paraformaldehyde in PBS and sectioned at E17.

Histology. For immunohistochemistry, the retina was dissected free of the eye cup and fixed with $4 \%$ paraformaldehyde in PBS for $2 \mathrm{~h}$ at $4^{\circ} \mathrm{C}$. The tissue was sunk in $30 \%$ sucrose/PBS, frozen in OCT compound, and sectioned at $20 \mu \mathrm{m}$ in a cryostat. Sections were mounted on gelatin-subbed slides, treated with $0.1 \%(\mathrm{w} / \mathrm{v})$ Triton X-100 in PBS for $10 \mathrm{~min}$ at room temperature, blocked with 5\% skim milk in PBS for $30 \mathrm{~min}$, and then incubated successively with primary and secondary antibodies. In situ hybridization was performed using NBT (nitro-blue tetrazolium chloride)/BCIP (5-bromo-4-chloro-3'-indolyphosphate p-toluidine salt) for colorimetric detection of digoxigenin-labeled riboprobes (Yamagata et al., 2002).

Cell culture. Human embryonic kidney (HEK) 293 cells obtained from ATCC were transfected with expression vectors containing a CMV promoter, using DMRIE-C (Invitrogen). Stably expressing cells were selected in G418-supplemented medium, and highly expressing clones were used for further studies. To cluster Sidekick- 2 on the surface of HEK cells, cultures were incubated with $2 \mu \mathrm{g} / \mathrm{ml} \mathrm{CS} 22 \mathrm{IgG}$, rinsed with culture medium, incubated with Alexa568-coupled goat anti-mouse antibodies, rinsed again, and fixed with $4 \%$ paraformaldehyde/PBS. The cells were methanol-treated at $-20^{\circ} \mathrm{C}$ for $15 \mathrm{~min}$, and stained with rabbit anti-myc antibodies, followed by Alexa488-coupled goat anti-rabbit antibodies.

Retinal cells were dissociated from embryonic chicks at E16 using papain (Worthington) and plated onto transfected HEK cells. The cocultures were maintained in Neurobasal medium (Invitrogen) with $10 \%$ $(\mathrm{v} / \mathrm{v})$ FCS and 2\% (v/v) B27 (Invitrogen) for $4 \mathrm{~d}$ before being fixed and stained. To doubly stain cultures for visinin plus anti-SV2, which are both IgG1 antibodies, we used the Zenon technology kit (Invitrogen) according to the manufacturer's instructions.

\section{Results \\ Localization and function of Sidekick-2 depend on its PDZ-binding motif}

Sidekick proteins bear a C-terminal hexapeptide sequence, -GFSSFV, which is perfectly conserved in all known vertebrates and invertebrate orthologues (Table 1). This sequence is predicted to bind PDZ domains, with the terminal tripeptide $\mathrm{S} / \mathrm{T}-\mathrm{x}-\mathrm{V}$, called a type I PDZ-binding motif, being the critical determinant (Songyang et al., 1997). To ask whether this canonical PDZ-binding motif is required for synaptic localization of Sidekick proteins, we analyzed the large, easily visualized synapses that photoreceptors form onto interneurons (horizontal and bipolar cells) in the outer plexiform layer of the retina. Sidekick-2 but not Sidekick-1 is expressed by photoreceptors and present at these synapses (Yamagata et al., 2002) (Fig. 1a-d). We therefore generated expression vectors encoding GFP plus wild-type Sidekick-2, or a Sidekick-2 mutant lacking the last three aa (Sdk2 $\Delta$ SFV). Using in ovo electroporation, we introduced these constructs into the optic vesicle of chick embryos. Because gene transfer is most efficient at embryonic day (E) 2, but synapses are not mature until E17, we used a PiggyBac transposon-transposase system, which results in genomic integration of introduced sequences, thereby allowing stable, long-term expression (Yamagata and Sanes, 2008). Transduced cells were recognizable by coexpression of GFP. Wild-type Sidekick-2 was concentrated at photoreceptor synapses, in a pattern indistinguishable from that of the endogenous protein (Fig. $1 e, g$ ). In contrast, $\mathrm{Sdk} 2 \Delta \mathrm{SFV}$ protein was diffusely distributed in photoreceptor cells (Fig. $1 f, h$ ). These results 
demonstrate that that the C-terminal PDZ-binding motif in Sidekick-2 is important for its synaptic localization.

We next asked whether Sidekick-2 function requires its $\mathrm{C}$ terminus. We could not use photoreceptors for this purpose, because roles of Sidekicks in these cells have not yet been defined. Instead, we assessed targeting of processes in the inner plexiform layer (IPL). Processes of amacrine and bipolar cells arborize in one or a few sublaminae within the IPL, where they form synapses on similarly sublamina-restricted dendrites of retinal ganglion cells (Masland, 2001; Wässle, 2004). There are $\geq 10$ sublaminae in the chick IPL, but we follow the convention (Ramón y Cajal, 1892) of dividing the IPL into five parallel slabs of equal width, S1S5. Synapses containing Sidekick-2 are concentrated in two sublaminae of the IPL: most are in the outer portion of S2, and a minority are in the outer portion of S4. Overexpression of Sidekick-2 in cells that are normally Sidekick-2-negative redirects their processes to S2 and S4 (Yamagata et al., 2002; Yamagata and Sanes, 2008) (Fig. 2a,b,d,e). In contrast, overexpression of Sidekick- $2 \Delta \mathrm{SFV}$, or of a Sidekick-2 mutant lacking most of the cytoplasmic domain (Sidekick-2 $\Delta$ Cyto) had no detectable effect of the laminar positioning of processes in the IPL (Fig. $1 c, f$, and data not shown). This result indicates that the PDZ-binding motif is required for Sidekick-2 to direct laminar specificity.

Sidekicks and Dscams bind MAGI and PSD-95 family members

To identify binding partners for the C-terminal domain of Sidekicks, we performed yeast two-hybrid screens (Fields and Song, 1989), using the C-terminal 50 aa of Sidekick-1 and Sidekick-2 as baits. Approximately $1 \times 10^{7}$ clones from a brain library and $4 \times 10^{6}$ clones from a spinal cord library were screened. Positive clones were retested to verify the specificity of the interaction, and then inserts were sequenced and identified.

The verified interactors obtained in these screens encoded proteins with PDZ domains. They included three of four members of the PSD-95 family (PSD-95/SAP90/DLG4, chapsyn110/ PSD93/DLG2, and SAP102/DLG3), two of three members of the MAGI family (MAGI-1/BAP1/WWP3/TNRC19 and MAGI-2/SSCAM/AIP/KIAA0705), Pist/Cal (PDZ domain protein interacting specifically with TC10/cystic fibrosis transmembrane conductance regulator-associated ligand), Cipp/PatJ (Channelinteracting PDZ domain protein/Pals1-associated tight junction protein), and Par6 $\alpha$ (Kurschner et al., 1998; Neudauer et al., 2001; Funke et al., 2005) (supplemental Table 1, available at www.jneurosci.org as supplemental material). The isolated fragments suggested that Sidekicks bind to PDZ domains 2 and/or 3 in MAGI proteins and PDZ domain 3 in PSD-95 proteins. All PDZ domain-containing fragments isolated bound with similar strength to Sidekick-1 and Sidekick-2, and reacted as well with the $\mathrm{C}$-terminal 7 aa as with the $\mathrm{C}$-terminal 50 aa (data not shown). Thus, binding of Sidekicks to the PDZ domain-containing fragments can be entirely accounted for by their $\mathrm{C}$ termini.

Next, we used the two-hybrid system to assess interactions of the PDZ domain-containing fragments isolated using Sidekicks with PDZ-binding C termini of Dscams (Table 2). Using the growth rate of doubly transformed yeast as an approximate indicator of binding strength, we found that the $\mathrm{C}$ termini of Dscams bound similarly to the $\mathrm{C}$ termini of Sidekicks, despite differences in their sequences (Dscams:-KSYTLV; Sidekicks:-GFSSFV). In contrast, preferences of three other PDZ-binding synaptic components-the NMDA receptor $2 \mathrm{~B}$ subunit (C-terminal: -SIESDV), 

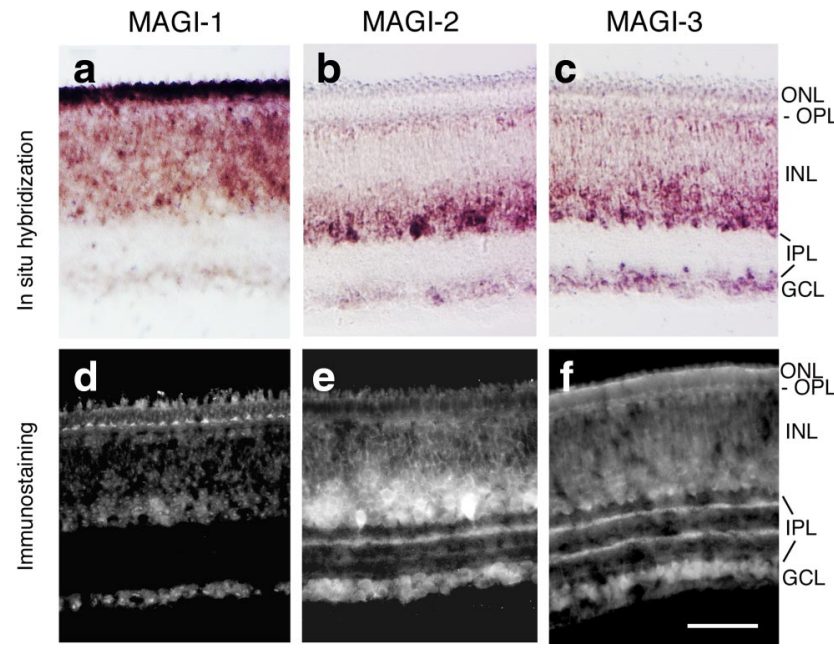

Figure 4. Differential localization of MAGI-1-3 in retina. $\boldsymbol{a}-\boldsymbol{c}$, Expression of MAGI-1-3 in E16 retina assessed by in situ hybridization. $\boldsymbol{d}-\boldsymbol{f}$, Localization of MAGI-1-3 proteins in E16 retina assessed by immunohistochemical staining. MAGI- 1 is expressed by photoreceptors and cells in the inner nuclear layer, and the protein is highly concentrated in the OPL. MAGI-2 and MAGI-3 are expressed by cells in the inner nuclear and ganglion cell layers, and the proteins are highly concentrated in distinct sublaminae within the IPL. Abbreviations as in Figure 1. Scale bar: $\boldsymbol{f}, 20 \mu \mathrm{m}$.
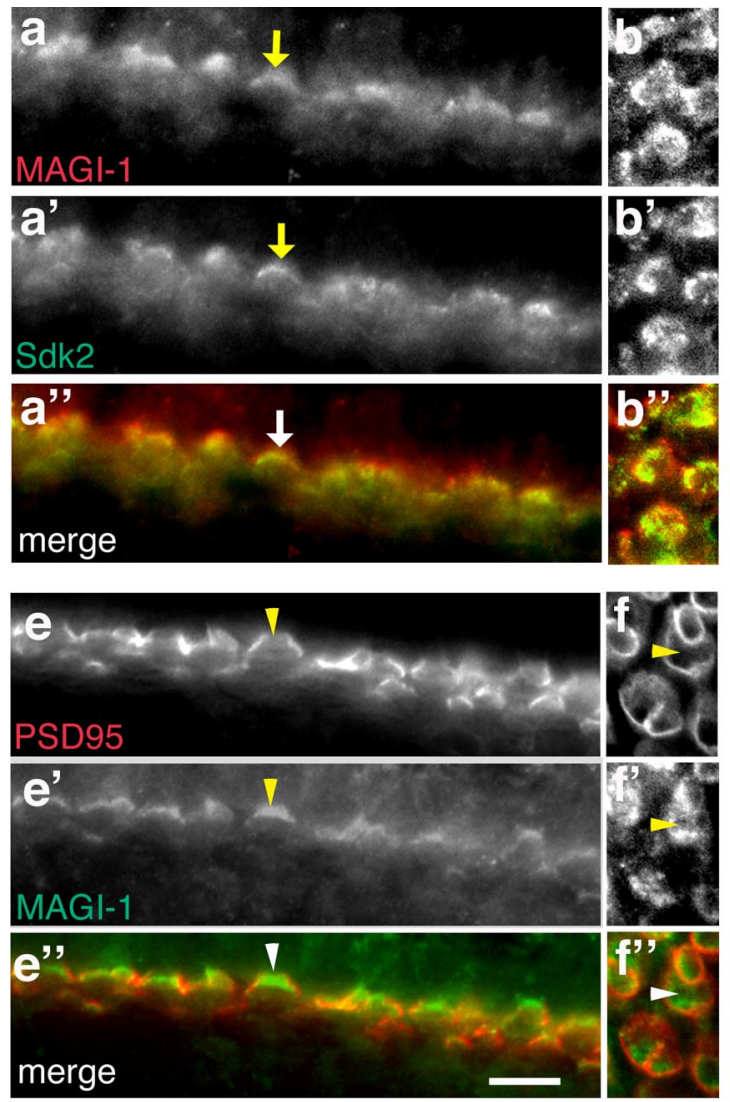

and the adhesion molecules neuronal cell adhesion molecule (NrCAM; -AMNSFV) and neuroligin-1 (-HSTTRV)— differed from each other and from Sidekicks and Dscams (Table 2). For example, the NMDA-receptor 2B did not bind detectably to the MAGI fragments; neuroligin- 1 bound only to the MAGI-derived fragment that contained PDZ domain 1 (Iida et al., 2004); and NrCAM preferred PSD-95 family members to MAGI family members. Thus, within the limited set of synaptic proteins tested, the PDZ binding patterns of Sidekicks and Dscams are most similar to each other.

To ask whether Sidekicks and Dscams interact with PSD-95 and MAGI family members in vertebrate cells, we assessed the extent to which they colocalized when introduced into human embryonic kidney (HEK) 293 cells. In one assay, epitope-tagged fragments of one MAGI family member, MAGI-1, or one PSD-95 family member, SAP-102, were coexpressed with Sidekick-2, Dscam, or the Sidekick-2 $\Delta$ SFV mutant described above. Each was diffusely distributed when expressed alone, but Sidekick-2 and Dscam could be induced to cluster by incubating live cells successively with a specific antibody and a fluorophore-tagged secondary antibody. Antibody-mediated aggregation of Sidekick-2 or Dscam induced coaggregation of MAGI-1 and SAP-102, whereas aggregation of Sidekick-2 $\Delta$ SFV had no effect on MAGI-1 or SAP102 distribution (Fig. $3 a$ ).

In a second assay, we introduced Dscams or Sidekicks into cells expressing full-length MAGI-1, then cultured cells at high density. The homophilic binding of Sidekicks and Dscams con-
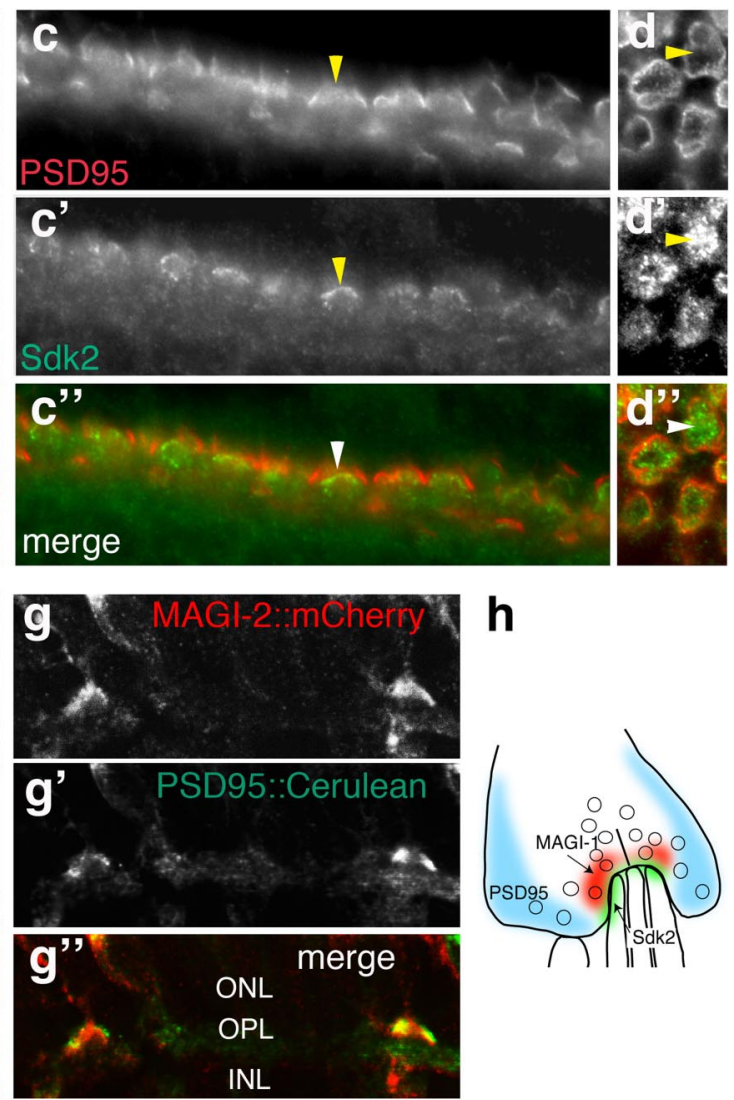

Figure 5. Differential localization of PDZ domain proteins and Sidekick-2 in the outer retina. $\boldsymbol{a}-\boldsymbol{f}$, Double immunofluorescence staining of E19 photoreceptor terminals with antibodies to MAGI- 1 and Sidekick-2 $(\boldsymbol{a}, \boldsymbol{b})$, PSD-95 and Sidekick-2 $(\boldsymbol{c}, \boldsymbol{d})$, or MAGI-1 and PSD-95 $(\boldsymbol{e}, \boldsymbol{f})$. Both en face views $(\boldsymbol{a}, \boldsymbol{c}, \boldsymbol{e})$ and cross sections $(\boldsymbol{b}, \boldsymbol{d}, \boldsymbol{f})$ are shown. Arrows highlight areas in which MAGI-1 and Sidekick-2 overlap; arrowheads highlight areas in which PSD-95 localization is complementary to that of Sidekick-2 and MAGI-1. g, MAGI-2-fused mCherry and PSD-95-fused cyan fluorescent protein were expressed by electroporation in E17 photoreceptors. Exogenous MAGI-2 and PSD-95, like endogenous proteins are differentially localized at the photoreceptor terminals. $\boldsymbol{h}$, Schematic showing differential localization of PSD-95, MAGI-1 and Sidekick-2 in photoreceptor terminals. Abbreviations as in Figure 1. Scale bar: (in $\left.\boldsymbol{e}^{\prime \prime}\right) \boldsymbol{a}-\boldsymbol{g}^{\prime \prime}, 1 \mu \mathrm{m}$. 
centrates these adhesion molecules at points of contact between cells that express them (Yamagata and Sanes, 2008). MAGI-1 was diffusely distributed in HEK cells when expressed alone but concentrated at cell-cell contact sites when coexpressed with Sidekicks or Dscams (Fig. $3 b$ ). A Sidekick-1 protein in which the $\mathrm{C}$ terminus was occluded by fusion to GFP aggregated at cell-cell contact sites, but failed to recruit MAGI-1 (data not shown). MAGI-2 was also aggregated by Sidekick-1 but not by Sidekick-1-GFP (Fig. 3c). Together, these results demonstrate that Sidekicks and Dscams interact with PSD-95 and MAGI family members at the plasma membrane of vertebrate cells.

Sidekick-2 differentially recruits

MAGI-1 and PSD-95 to

photoreceptor synapses

As a prelude to analyzing roles of Sidekickand Dscam-PDZ protein interactions in vivo, we assessed the expression of the PDZ domain-containing binding partners in retina. In situ hybridization showed that each of the three MAGI genes was expressed by subsets of retinal neurons (Fig. $4 a-c$ ), and immunohistochemical staining showed that MAGI 1-3 proteins, like Sidekicks and Dscams (Yamagata et al., 2002; Yamagata and Sanes, 2008), were concentrated at subsets of synapses in the outer and inner plexiform layers (Fig. $4 d-f$ ). Strikingly, MAGI-1 but not MAGI-2 or MAGI-3 was expressed at high levels by photoreceptors and con-

centrated at synapses in the outer plexiform layer. PSD-95 family members and Pist/Cal were also expressed by subsets of retinal cells (supplemental Fig. $1 a-c$, available at www.jneurosci.org as supplemental material). PSD-95 was present at high levels in the outer plexiform layer, but at low levels in the inner plexiform layer (supplemental Fig. 1e, available at www.jneurosci.org as supplemental material).

Photoreceptor terminals form synapses on both horizontal and bipolar cell processes in the outer plexiform layer, with the latter forming an annulus around the former (Fig. $5 \mathrm{~h}$ ). These synapses bore Sidekick-2, PSD-95, and MAGI-1 but not Sidekick-1, MAGI-2, or MAGI-3 (Figs. 1, 3) (Yamagata et al., 2002). MAGI-1 was concentrated in the core domain, indicating an association with horizontal cell synapses, whereas PSD-95 was concentrated in the annular domain, indicating an association with bipolar cell synapses (Fig. $4 a-f$ ). The presynaptic localization of PSD-95 contrasts with its postsynaptic localization at many central synapses, but is consistent with its presence in photoreceptor terminals in rodents (Koulen et al., 1998). Remarkably, Sidekick-2 was colocalized with MAGI-1 in the core domain and present at significantly lower levels in the annular domain (Fig. 4a-d). When tagged MAGI-1 and PSD-95 were coexpressed in photoreceptor cells, the cognate proteins were differentially recruited to core and annular domains, respectively (Fig. 4g,h), confirming that photoreceptor cells can differentially deliver these proteins to distinct subcellular domains.

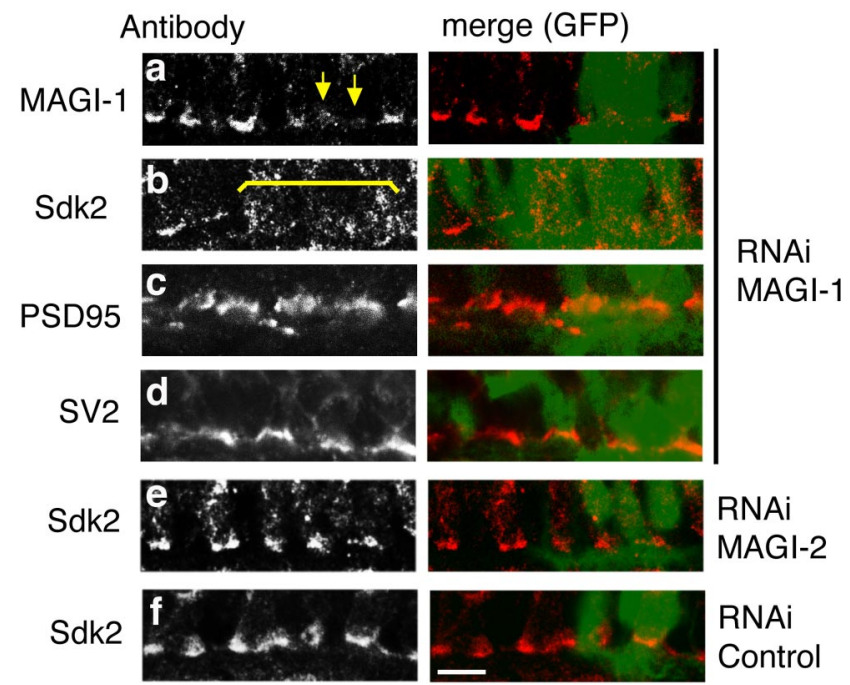

Figure 7. Depletion of MAGI-1 alters synaptic localization of Sidekick-2 in photoreceptors. Outer plexiform layer of retinae transduced with transposons that express GFP with interfering RNA specific for MAGI-1, MAGI-2, or an unrelated control sequence. $\boldsymbol{a}-\boldsymbol{d}$, Transduced cells were identified by expression of GFP (merge). MAGI-1 RNAi led to loss of MAGl-1 (arrows in $\boldsymbol{a}$ ) and Sidekick-2 (bracket in $\boldsymbol{b}$ ) but not PSD-95 (c) or SV2 (d) concentrations from photoreceptor synapses. $\boldsymbol{e}, \boldsymbol{f}, \mathrm{MAGI}-2 \mathrm{RNAi}$ and control had no effect on distribution of these synaptic components. Scale bar: $f, 5 \mu \mathrm{m}$. 

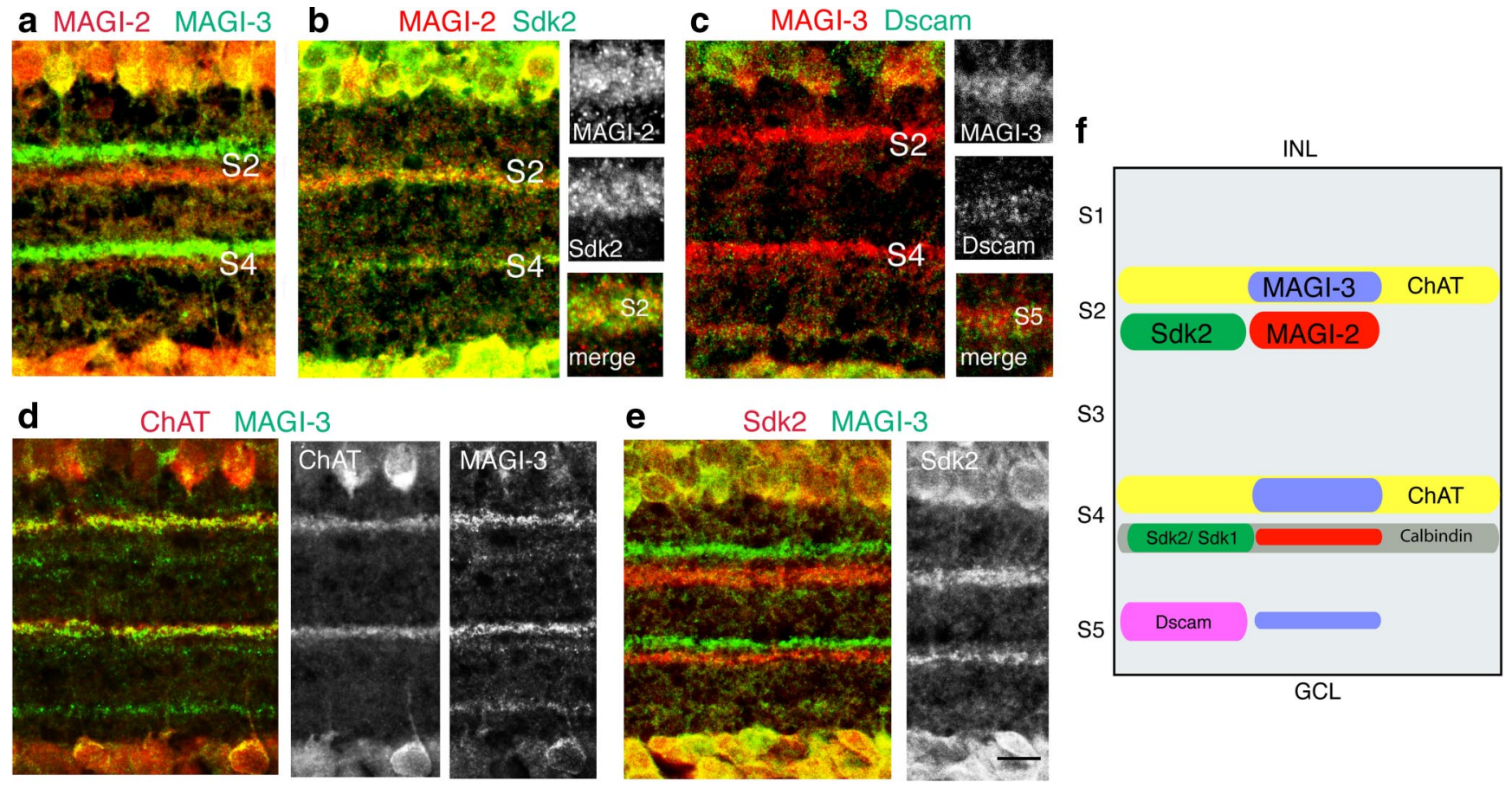

Figure 8. Association of MAGI-2 and MAGI-3 with nonoverlapping sublaminae in the IPL. $\boldsymbol{a}-\boldsymbol{e}$, Sections of the inner plexiform layer were stained with antibodies to MAGI-2 and MAGI-3 (a), MAGI-2 and Sidekick-2 (b), MAGI-3 and Dscam (c), MAGI-3 and choline acetyltransferase (ChAT; $\boldsymbol{d}$ ), or Sidekick-2 and MAGI-3 (e). $\boldsymbol{f}$, Results from these and other double-label studies are summarized. The two bands rich in MAGI-2 correspond to those that contain Sidekicks and one of three MAGI-3-positive bands corresponds to that rich in Dscam. Insets in $\boldsymbol{b}$ and $\boldsymbol{c}$ show portions of the IPL at higher power. Scale bar: (in $\boldsymbol{e}$ ) $\boldsymbol{a}$ - $\boldsymbol{e}$ main panels, $5 \mu \mathrm{m} ; \boldsymbol{a}-\boldsymbol{e}$ insets, $2.5 \mu \mathrm{m}$.

These results suggest that Sidekick-2 associates preferentially with MAGI-1 over PSD-95 in photoreceptors. To test this idea, we analyzed the distribution of MAGI-1 and PSD-95 in photoreceptors cultured on Sidekick-2-expressing HEK cells, reasoning that it would recruit Sidekick-2 in the photoreceptors as it does in the HEK cells (Fig. 3b).

Photoreceptors, identified with antibodies to the specific marker, visinin (Bruhn and Cepko, 1996), extended short processes on HEK cells (Fig. $6 a, d, g$ ). MAGI-1 clustered at sites of contact between photoreceptor processes and Sidekick-2expressing HEK cells, but not at sites of contact with Sidekick1expressing or nontransfected HEK cells (Fig. $6 a-c, j$ ). The distribution of PSD-95 was not affected by contact with either transfected or nontransfected HEK cells (Fig. 6d-f). In contrast, Sidekick recruited MAGI and PSD-95 equally well when all three proteins are coexpressed in HEK cells (Fig. $6 k, l$ ). Thus, factors specific to photoreceptors lead to a specific association between Sidekick and MAGI.

Interestingly, SV2, a component of synaptic vesicles, was aggregated in stretches of photoreceptor processes that contacted Sidekick-2-expressing cells (Fig. $6 g-i$ ), raising the possibility that Sidekick-mediated transsynaptic interactions can promote presynaptic differentiation, as has been shown for other synaptic adhesion molecules such as neuroligin, SynCAM, and SIRP- $\alpha$ (Scheiffele et al., 2000; Biederer et al., 2002; Umemori and Sanes, 2008).

\section{Association with MAGI 1 is required for synaptic localization of Sidekick-2}

To ask whether synaptic localization of Sidekick-2 in vivo depends on MAGI-1, we identified an interfering RNA that targeted MAGI-1 effectively in cultured cells (supplemental Fig. $2 a$, available at www.jneurosci.org as supplemental material), incorpo- rated it into a microRNA-based vector that coexpressed GFP, and electroporated it into retina as described above for Sidekick. Expression of the interfering RNA led to a substantial decrease in MAGI-1 levels (Fig. 7a). Sidekick-2 levels were also decreased in GFP-positive, MAGI-1-depleted photoreceptors, but not in their GFP-negative, MAGI-1-positive neighbors (Fig. 7b). As control, we used vectors encoding GFP alone or along with an interfering RNA that targeted MAGI-2 (supplemental Fig. $2 b$, available at www.jneurosci.org as supplemental material), which is not expressed by photoreceptors (see above); neither had a discernible effect on MAGI-1 or Sidekick-2 levels in photoreceptors (Fig. $7 e, f$, and data not shown). We conclude that MAGI-1 is required for localization of Sidekick-2. We were unable to determine, however, whether total levels of Sidekick-2 were decreased, or whether protein that would otherwise be concentrated at the synapse was diffusely distributed in the absence of MAGI-1.

We also asked whether loss of MAGI-1 and Sidekick-2 from the presynaptic membrane perturbed localization of other components of photoreceptor terminals. PSD-95 and SV2 were not detectably affected by the loss of MAGI-1 (Fig. 7c,d). Thus, although Sidekick can recruit synaptic vesicles in photoreceptors, it is not required for vesicle recruitment in vivo.

\section{Association with MAGI 2 is required for synaptic function of Sidekick-2}

As noted above, MAGI-2 and MAGI-3 but not MAGI-1 are concentrated in specific sublaminae of the IPL (Fig. 3). Double-label immunohistochemistry revealed that MAGI-2 and MAGI-3-rich sublaminae are nonoverlapping, indicating that MAGI-2 and MAGI-3 are present in distinct synapses (Fig. $8 a$ ). We then asked whether either MAGI protein was codistributed with Sidekicks or Dscams. The two bands rich in MAGI-2 corresponded to those that contain Sidekick-positive synapses, and one of three bands 

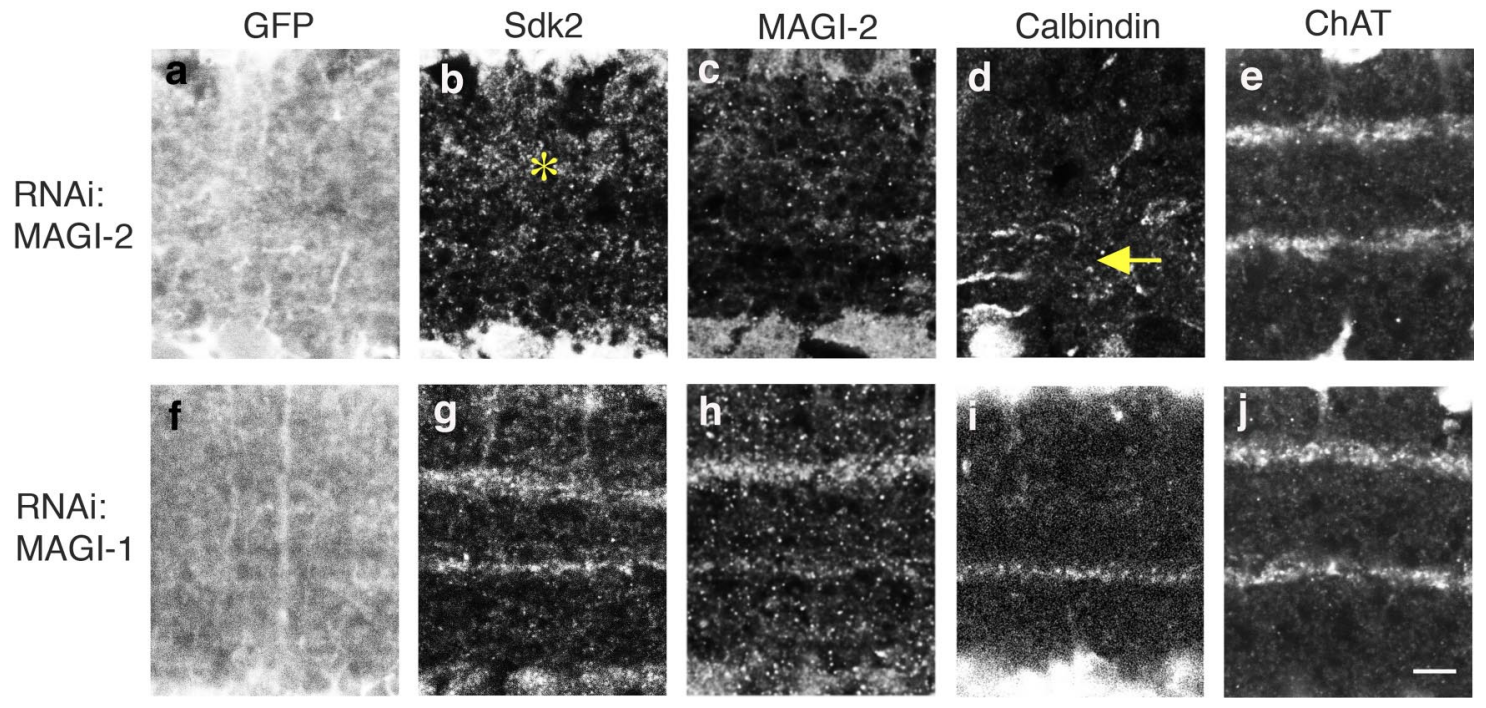

Figure 9. Depletion of MAGI-2 in IPL disrupts Sidekick-positive sublaminae in the inner plexiform layer. $\boldsymbol{a}-\boldsymbol{e}$, Inner plexiform layer of retinae that had been infected with retroviruses that express GFP plus interfering RNA specific for MAGI-2. Infected cells were identified by expression of GFP. In the infected area, Sidekick-2 sublaminae were diffuse (asterisk) and Sidekick-2-expressing processes marked by calbindin (arrow) were dispersed. Choline acetyltransferase (ChAT)-positive sublaminae above the Sidekick-2/MAGI-2-positive sublaminae were not affected by MAGI-2 depletion. $\boldsymbol{f}-\boldsymbol{j}$, Introduction of MAGI-1 interfering RNA had no effect on markers assayed. Scale bar: (in $\boldsymbol{j}$ ) $\boldsymbol{a}-\boldsymbol{j}, 5 \mu \mathrm{m}$.

rich in MAGI-3 corresponded to that in which Dscam-positive synapses are concentrated (Fig. $8 b, c$, and data not shown). Confocal images suggested that MAGI-2 and Sidekick-2 were present in the same synaptic puncta, as were MAGI-3 and Dscam (Fig. $8 b, c$, insets). The two Dscam-negative MAGI-3-positive bands contained few if any DscamL-positive or Sidekick-positive synapses, but instead corresponded to sublaminae in which cholinergic starburst amacrines arborize (Fig. $8 d-f$ ).

For functional analysis, we used RNA interference to deplete MAGI-2 from retina, and asked whether its loss affected the sublaminar concentration of Sidekicks, with which it is localized. We used retroviral vectors for this study rather than transposons, to transduce large groups of neuron (Fig. 9a,f). RNA interference (RNAi) directed at MAGI-2 but not at MAGI-1 depleted MAGI-2 both in cultured cells (supplemental Fig. $2 b$, available at www. jneurosci.org as supplemental material) and in the IPL (Fig. $9 c, h$ ). RNAi directed at MAGI-2 but not at MAGI-1 also led to a strong decrease in Sidekick-2 immunoreactivity (Fig. 9b,g). Thus, consistent with their expression patterns, MAGI-1 and MAGI-2 are required for localization of Sidekick-2 in the outer and inner plexiform layers, respectively.

When Sidekick-2 is depleted from retinal neurons, their processes defasciculate and are no longer confined to specific sublaminae within the IPL (Yamagata and Sanes, 2008). Loss of Sidekick immunoreactivity from the IPL following downregulation of MAGI-2 could also reflect defasciculation, but could also result from redistribution of the protein within otherwise unaltered processes. To distinguish between these alternatives, we stained retinae with antibodies to calbindin, a soluble protein coexpressed by Sidekick-2-positive cells that arborize in S4 (Fig. 9d) (Yamagata and Sanes, 2008). Calbindin-positive processes were present but no longer confined to $\$ 4$ following depletion of MAGI-2 (Fig. 9d,i). In contrast, laminar markers such as choline acetyltransferase and cadherin 4 (R-cadherin), which were not colocalized with MAGI-2, were unaffected by MAGI-2 depletion (Fig. $9 e$, , and data not shown). These results demonstrate that MAGI proteins are required for Sidekick-2 to promote laminaspecific synapse formation in the IPL.

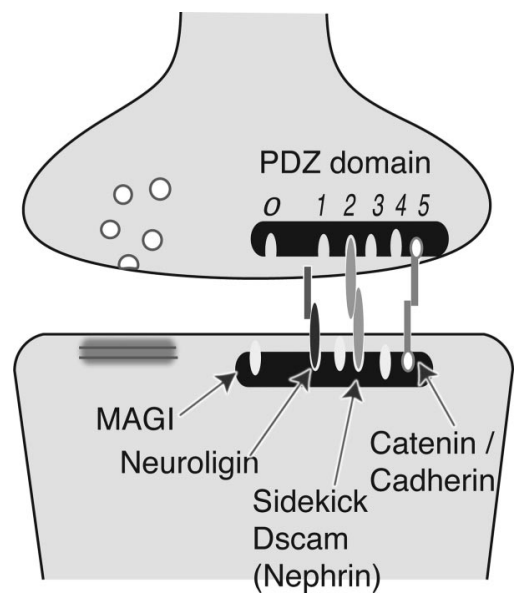

Figure 10. Model for roles of MAGI proteins and Sidekicks in synapse specificity and formation. In this model, neuroligins bind to PDZ domain 1 in MAGl proteins, target recognition molecules such as Sidekicks and Dscams bind to PDZ domains 2 and 3, and catenins link cadherins with PDZ domain 5. Thus, MAGIs form a scaffold for multiple transsynaptic organizing molecules with the recognition molecules biasing synaptic interactions in favor of appropriate partners.

\section{Discussion}

Mechanisms that promote aggregation of neurotransmitter receptors in the postsynaptic membrane have been analyzed in considerable detail (references in Introduction), but very little is known about how other synaptic components become localized to synaptic sites. Our study began with the observation that a set of four synaptic recognition molecules, two Sidekicks and two Dscams, are predicted to bind PDZ domains. We found that Sidekicks and Dscams do indeed bind PDZ domain-containing proteins, and asked whether the interaction is critical for the localization or function of Sidekicks in retina, the only portion of the nervous system in which they have so far been analyzed (Yamagata et al., 2002; Yamagata and Sanes, 2008).

Our main findings are as follows: (1) Sidekicks and Dscams interact, via their $\mathrm{C}$ termini, with members of the MAGI and 
PSD-95 families of multi-PDZ domain synaptic scaffolding proteins. (2) Individual members of both families are expressed by distinct subsets of neurons and the proteins are localized to distinct synapses, much as has been found for Sidekicks and Dscams. (3) In photoreceptor nerve terminals, which contain both MAGI-1 and PSD-95, Sidekick-2 preferentially associates with and recruits MAGI-1, even though it interacts similarly with both in heterologous cells. (4) Deletion of the C terminus of Sidekick-2 or knockdown of MAGI-1 prevents synaptic localization of Sidekick to the presynaptic membrane of photoreceptors in vivo. (5) Deletion of the $\mathrm{C}$ terminus of Sidekick-2 or knockdown of MAGI-2 blocks the ability of Sidekick to promote laminaerestricted arborization of processes in the inner plexiform layer. Together, these results establish that the function and localization of Sidekick-2 (and by implication, Sidekick-1 and Dscams) require interaction with MAGI scaffolding proteins.

These results raise new questions that can now be addressed to provide a more satisfying understanding of how synapses form. First, how does MAGI localize Sidekick to synapses? The simplest model is that binding sites in a MAGI-containing scaffold immobilize Sidekick in synaptic membranes. Rapsyn- and gephyrindependent aggregation of acetylcholine and glycine receptors, respectively, involve such aggregation, at least in part (Banks et al., 2003; Fritschy et al., 2008). However, PDZ domain proteins have been implicated in trafficking of glutamate receptors (Ehrlich et al., 2004; Prybylowski et al., 2005; Craig et al., 2006), so it is possible that the interaction regulates delivery to the synapse, in addition to or instead of immobilization.

Second, why does Sidekick-2 associate preferentially with MAGI-1 over PSD-95 in nerve terminals? Preliminary attempts to assess binding strength or preference have not revealed striking differences between Sidekick-MAGI and Sidekick-PSD-95 interactions (Fig. 4k) (M. Yamagata, unpublished observations). One possibility is that a post-translational modification to one of the binding partners affects its affinity for the other. For example, phosphorylation of the PDZ domain-binding site of the GluR2 glutamate receptor subunit decreases its affinity for one PDZ protein, GRIP-1, without affecting its affinity for another, PICK-1 (Chung et al., 2000). Sidekicks have serines at the -3 and -4 positions (Table 1) that are potential substrates for serine/ threonine kinases. An alternative is that other binding partners present at synapses shift the balance. For example, the PDZ domains in PSD-95 to which Sidekick can bind might be occupied by higher-affinity ligands.

Third, what is the significance of the conserved C-terminal hexapeptide in Sidekicks (Table 1)? PDZ-binding sequences are conserved to some degree in many transmembrane molecules (e.g., Dscam, Table 1), but Sidekick's degree of conservation across multiple phyla is unusual. There might be novel binding partners highly specific for this hexapeptide that our screens did not reveal. Alternatively, the sequence may have been selected to recognize a specific subset of PDZ domains with different affinities. The preferential association of Sidekick with MAGIs over PSD-95 in vivo may exemplify this quality.

Fourth, does localization or function of other synaptic recognition or adhesion molecules require MAGIs in particular or PDZ proteins in general? Numerous proteins in this class terminate in PDZ-binding motifs, including neurologins, neurexins, nephrins, nectins, SynCAMs, Eph kinases, ephrinsB, and NrCAM. For several of them, PDZ domain-containing binding partners have been identified by yeast two-hybrid screens, coexpression in heterologous cells, or coimmunoprecipitation (Yamada et al., 2003; Iida et al., 2004; Meyer et al.,
2004; Davey et al., 2005; Hirabayashi et al., 2005; Levinson et al., 2010). It is thus tempting to speculate that the interactions defined here are emblematic of a more general phenomenon.

Finally, what role does MAGI play in Sidekick-dependent laminar specificity? Perhaps, the simplest model is that function requires a high concentration of Sidekick at developing synapses. In this view, the crucial role of MAGI would be to aggregate Sidekick. An intriguing alternative, however, is that MAGI acts by coordinating multiple transsynaptic interactions (Fig. 10). MAGIs are associated with both presynaptic and postsynaptic membranes in chick retina and rodent hippocampus (Yamada et al., 2003). Both neuroligins and cadherins, which have been implicated in regulation of synapse formation and synaptic efficacy (Arikkath and Reichardt, 2008; Südhof, 2008), interact with MAGIs. Neuroligins, which are present in postsynaptic membranes of many synapses, bind to the first of five PDZ domains in MAGI-2 and MAGI-3 (Iida et al., 2004; Meyer et al., 2004). Neurexins, the presynaptic binding partners of neuroligins, also bear PDZ-binding $\mathrm{C}$ termini that influence their localization, although the binding partners have not yet been identified (Südhof, 2008). Cadherins, which are present in both presynaptic and postsynaptic membranes of many synapses (Yamagata et al., 1995; Arikkath and Reichardt, 2008), bind to $\beta$ - and $\delta$-catenins, which in turn bind the fifth PDZ domain in MAGI (Ide et al., 1999; Nishimura et al., 2002). MAGIs may also be involved in recruitment of neurotransmitter receptors such as AMPA- and NMDA-type glutamate receptors (Deng et al., 2006). As shown here, Sidekicks and Dscams bind to PDZ domains 2 and/or 3 of MAGI. Based on these findings, we suggest that MAGI provides a means by which target recognition molecules that bias connectivity in favor of appropriate partners (e.g., Sidekicks and Dscams at PDZ 2/3) can recruit other adhesive proteins that promote synaptic maturation and regulate synaptic efficacy (e.g., neuroligin at PDZ1 and cadherin at PDZ5). If this model is correct, it may be possible to identify additional candidate target recognition molecules by screening for ligands of MAGI PDZ domains 2 and 3. In this regard, it is encouraging that nephrin, the mammian orthologue of the Caenorhabditis elegans synaptic specificity molecule SYG-2, also binds to MAGI PDZ domains 2/3 (Shen et al., 2004; Hirabayashi et al., 2005).

\section{References}

Amano K, Fujii M, Arata S, Tojima T, Ogawa M, Morita N, Shimohata A, Furuichi T, Itohara S, Kamiguchi H, Korenberg JR, Arata A, Yamakawa K (2009) DSCAM deficiency causes loss of pre-inspiratory neuron synchroneity and perinatal death. J Neurosci 29:2984-2996.

Arikkath J, Reichardt LF (2008) Cadherins and catenins at synapses: roles in synaptogenesis and synaptic plasticity. Trends Neurosci 31:487-494.

Banks GB, Fuhrer C, Adams ME, Froehner SC (2003) The postsynaptic submembrane machinery at the neuromuscular junction: requirement for rapsyn and the utrophin/dystrophin-associated complex. J Neurocytol 32:709-726.

Biederer T, Sara Y, Mozhayeva M, Atasoy D, Liu X, Kavalali ET, Südhof TC (2002) SynCAM, a synaptic adhesion molecule that drives synapse assembly. Science 297:1525-1531.

Bruhn SL, Cepko CL (1996) Development of the pattern of photoreceptors in the chick retina. J Neurosci 16:1430-1439.

Cho KO, Hunt CA, Kennedy MB (1992) The rat brain postsynaptic density fraction contains a homolog of the Drosophila discs-large tumor suppressor protein. Neuron 9:929-942.

Chung HJ, Xia J, Scannevin RH, Zhang X, Huganir RL (2000) Phosphorylation of the AMPA receptor subunit GluR2 differentially regulates its interaction with PDZ domain-containing proteins. J Neurosci 20:7258-7267.

Craig AM, Graf ER, Linhoff MW (2006) How to build a central synapse: clues from cell culture. Trends Neurosci 29:8-20. 
Davey F, Hill M, Falk J, Sans N, Gunn-Moore FJ (2005) Synapse associated protein 102 is a novel binding partner to the cytoplasmic terminus of neurone-glial related cell adhesion molecule. J Neurochem 94:12431253.

Deng F, Price MG, Davis CF, Mori M, Burgess DL (2006) Stargazin and other transmembrane AMPA receptor regulating proteins interact with synaptic scaffolding protein MAGI-2 in brain. J Neurosci 26:7875-7884.

Ehrlich I, Malinow R (2004) Postsynaptic density 95 controls AMPA receptor incorporation during long-term potentiation and experience-driven synaptic plasticity. J Neurosci 24:916-927.

Elias GM, Funke L, Stein V, Grant SG, Bredt DS, Nicoll RA (2006) Synapsespecific and developmentally regulated targeting of AMPA receptors by a family of MAGUK scaffolding proteins. Neuron 52:307-320.

Feng G, Tintrup H, Kirsch J, Nichol MC, Kuhse J, Betz H, Sanes JR (1998) Dual requirement for gephyrin in glycine receptor clustering and molybdoenzyme activity. Science 282:1321-1324.

Feng W, Zhang M (2009) Organization and dynamics of PDZ-domainrelated supramodules in the postsynaptic density. Nat Rev Neurosci 10:87-99.

Fields S, Song O (1989) A novel genetic system to detect protein-protein interactions. Nature 340:245-246.

Fritschy JM, Harvey RJ, Schwarz G (2008) Gephyrin: where do we stand, where do we go? Trends Neurosci 31:257-264.

Fuerst PG, Koizumi A, Masland RH, Burgess RW (2008) Neurite arborization and mosaic spacing in the mouse retina require DSCAM. Nature 451:470-474.

Fuerst PG, Bruce F, Tian M, Wei W, Elstrott J, Feller MB, Erskine L, Singer JH, Burgess RW (2009) DSCAM and DSCAML1 function in self-avoidance in multiple cell types in the developing mouse retina. Neuron 64:484-497.

Funke L, Dakoji S, Bredt DS (2005) Membrane-associated guanylate kinases regulate adhesion and plasticity at cell junctions. Annu Rev Biochem 74:219-245.

Gautam M, Noakes PG, Mudd J, Nichol M, Chu GC, Sanes JR, Merlie JP (1995) Failure of postsynaptic specialization to develop at neuromuscular junctions of rapsyn-deficient mice. Nature 377:232-236.

Hirabayashi S, Mori H, Kansaku A, Kurihara H, Sakai T, Shimizu F, Kawachi H, Hata Y (2005) MAGI-1 is a component of the glomerular slit diaphragm that is tightly associated with nephrin. Lab Invest 85:1528-1543.

Hirao K, Hata Y, Ide N, Takeuchi M, Irie M, Yao I, Deguchi M, Toyoda A, Sudhof TC, Takai Y (1998) A novel multiple PDZ domain-containing molecule interacting with $N$-methyl-D-aspartate receptors and neuronal cell adhesion proteins. J Biol Chem 273:21105-21110.

Hung AY, Sheng M (2002) PDZ domains: structural modules for protein complex assembly. J Biol Chem 277:5699-5702.

Ide N, Hata Y, Deguchi M, Hirao K, Yao I, Takai Y (1999) Interaction of S-SCAM with neural plakophilin-related armadillo-repeat protein/deltacatenin. Biochem Biophys Res Comm 256:456-461.

Iida J, Hirabayashi S, Sato Y, Hata Y (2004) Synaptic scaffolding molecule is involved in the synaptic clustering of neuroligin. Mol Cell Neurosci 27:497-508.

Kim E, Sheng M (2004) PDZ domain proteins of synapses. Nat Rev Neurosci 5:771-781.

Koulen P, Fletcher EL, Craven SE, Bredt DS, Wässle H (1998) Immunocytochemical localization of the postsynaptic density protein PSD-95 in the mammalian retina. J Neurosci 18:10136-10149.

Kurschner C, Mermelstein PG, Holden WT, Surmeier DJ (1998) CIPP, a novel multivalent PDZ domain protein, selectively interacts with Kir4.0 family members, NMDA receptor subunits, neurexins, and neuroligins. Mol Cell Neurosci 11:161-172.

Levinson JN, Li R, Kang R, Moukhles H, El-Husseini A, Bamji SX (2010)
Postsynaptic scaffolding molecules modulate the localization of neuroligins. Neuroscience 165:782-793

Li X, Lobo N, Bauser CA, Fraser MJ Jr (2001) The minimum internal and external sequence requirements for transposition of the eukaryotic transformation vector piggyBac. Mol Genet Genomics 266:190-198.

Ly A, Nikolaev A, Suresh G, Zheng Y, Tessier-Lavigne M, Stein E (2008) DSCAM is a netrin receptor that collaborates with DCC in mediating turning responses to netrin-1. Cell 133:1241-1254.

Masland RH (2001) The fundamental plan of the retina. Nat Neurosci 4:877-886.

McAllister AK (2007) Dynamic aspects of CNS synapse formation. Annu Rev Neurosci 30:425-450.

Meyer G, Varoqueaux F, Neeb A, Oschlies M, Brose N (2004) The complexity of PDZ domain-mediated interactions at glutamatergic synapses: a case study on neuroligin. Neuropharmacology 47:724-733.

Neudauer CL, Joberty G, Macara IG (2001) PIST: a novel PDZ/coiled-coil domain binding partner for the rho-family GTPase TC10. Biochem Biophys Res Comm 280:541-547.

Nishimura W, Yao I, Iida J, Tanaka N, Hata Y (2002) Interaction of synaptic scaffolding molecule and beta-catenin. J Neurosci 22:757-765.

Prybylowski K, Chang K, Sans N, Kan L, Vicini S, Wenthold RJ (2005) The synaptic localization of NR2B-containing NMDA receptors is controlled by interactions with PDZ proteins and AP-2. Neuron 47:845-857.

Ramón y Cajal S (1892) La rétine des vertébrés. Cellule 9:119-257.

Sanes JR, Yamagata M (2009) Many paths to synaptic specificity. Annu Rev Cell Dev Biol 25:161-195.

Scheiffele P, Fan J, Choih J, Fetter R, Serafini T (2000) Neuroligin expressed in nonneuronal cells triggers presynaptic development in contacting axons. Cell 101:657-669.

Shen K, Fetter RD, Bargmann CI (2004) Synaptic specificity is generated by the synaptic guidepost protein SYG-2 and its receptor, SYG-1. Cell 116:869-881.

Songyang Z, Fanning AS, Fu C, Xu J, Marfatia SM, Chishti AH, Crompton A, Chan AC, Anderson JM, Cantley LC (1997) Recognition of unique carboxyl-terminal motifs by distinct PDZ domains. Science 275:73-77.

Strochlic L, Cartaud A, Labas V, Hoch W, Rossier J, Cartaud J (2001) MAGI-1c: a synaptic MAGUK interacting with MuSK at the vertebrate neuromuscular junction. J Cell Biol 153:1127-1132.

Südhof TC (2008) Neuroligins and neurexins link synaptic function to cog nitive disease. Nature 455:903-911.

Umemori H, Sanes JR (2008) Signal regulatory proteins (SIRPS) are secreted presynaptic organizing molecules. J Biol Chem 283:34053-34061.

Vazquez F, Grossman SR, Takahashi Y, Rokas MV, Nakamura N, Sellers WR (2001) Phosphorylation of the PTEN tail acts as an inhibitory switch by preventing its recruitment into a protein complex. J Biol Chem 276:48627-48630.

Wässle H (2004) Parallel processing in the mammalian retina. Nat Rev Neurosci 5:747-757.

Yamada A, Irie K, Deguchi-Tawarada M, Ohtsuka T, Takai Y (2003) Nectindependent localization of synaptic scaffolding molecule (S-SCAM) at the puncta adherentia junctions formed between the mossy fibre terminals and the dendrites of pyramidal cells in the CA3 area of the mouse hippocampus. Genes Cells 8:985-994.

Yamagata M, Sanes JR (2008) Dscam and Sidekick proteins direct laminaspecific synaptic connections in vertebrate retina. Nature 451:465-469.

Yamagata M, Herman JP, Sanes JR (1995) Lamina-specific expression of adhesion molecules in developing chick optic tectum. J Neurosci 15: 4556-4571.

Yamagata M, Weiner JA, Sanes JR (2002) Sidekicks: synaptic adhesion molecules that promote lamina-specific connectivity in the retina. Cell 110: $649-660$. 